\title{
Effect of oxygen plasma treatment on tensile strength of date palm fibers and their interfacial adhesion with epoxy matrix
}

https://doi.org/10.1515/secm-2017-0102

Received March 15, 2017; accepted September 2, 2017; previously published online October 14, 2017

Abstract: In recent years, natural fibers have received much attention from various industrial applications. As these fibers are lightweight, nonabrasive, low cost, ecofriendly and biodegradable, they can be sometimes considered as alternatives to synthetic fibers in lightweight composite structures. In this work, date palm fibers (DPFs) were treated by oxygen plasma at various plasma discharge power and exposure time. The effects of plasma treatment on tensile strength of DPF and interfacial adhesion between DPF and epoxy were determined by single fiber tensile test and microbond test, respectively. Scanning electron microscopy was used to investigate the surface morphologies of DPFs before and after the plasma treatment. The functional groups on the surface were studied by attenuated total reflectance-Fourier transform infrared spectroscope (ATR-FTIR). Decrease in hemicellulose and lignin content of DPF was indicated in ATRFTIR spectra of the treated sample with plasma treatment. The results show that plasma treatment cleans the fiber surface and increases the surface roughness by etching effect. Moreover, fiber surface modification significantly improves tensile properties of DPFs and interfacial shear stress (IFSS) of fiber/matrix. However, the effects of plasma power and exposure time on tensile properties and IFSS values of DPFs are not found significant. Moreover, Weibull statistics show that plasma treatment could not decrease the variability in fiber strength due to the nature of fibers.

Keywords: adhesion; date palm fibers (DPFs); epoxy; microbond test; oxygen plasma test.

*Corresponding author: Mohammad Saleh Ahmadi, Department of Textile Engineering, Yazd University, Yazd 89195-741, Iran, e-mail:ms.ahmadi@yazd.ac.ir. http://orcid.org/0000-0002-0581-4033 Maryam Gholami, Mohammad Ali Tavanaie and Mohammad Khajeh Mehrizi: Department of Textile Engineering, Yazd University, Yazd 89195-741, Iran

\section{Introduction}

Concern about the preservation of natural sources and recycling has led to renewed interest in biomaterials with the focus on renewable raw materials. As a result, new types of composites based on plant fibers have been developed in recent years [1]. In some cases plant fibers can be used as alternatives to mineral and glass fibers in lightweight composite structures, as they are lightweight, low cost, eco-friendly, renewable, biodegradable, less abrasive to tooling, and less irritating to the respiratory system of the workers [2-4].

Date palm fiber (DPF) is one of the most available plant fibers in the Middle East. It is also found in Northern Africa, the Canary Islands, Pakistan, India, and in the USA (California) [2, 5]. The fibers cover the stem of the date palm tree Phoenix dactylifera with a mesh structure, and with various diameters ranging from 100 to 1000 microns $[2,5]$. Comparing the properties of DPF with those of coir, hemp and sisal fibers, one can see that DPF has the lowest density and cost. Moreover, it has the highest annual world production and the highest value of specific modulus of elasticity per cost $[6,7]$. However, large quantities of the agricultural residues of date palm trees accumulate every year in different countries. It is estimated that the annual date palm agricultural wastes are more than $20 \mathrm{~kg}$ of dry leaves and fibers for each date palm tree [5]. These agricultural wastes can be used as sources of reinforcing fibers for polymeric matrices in composites. The compositions of the DPF are given in Table 1 [6]. Table 2 gives some mechanical properties of DPF which are reported in the literature $[2,5,7,8]$.

Besides the mentioned benefits for natural fibers, in general, and specifically for date palm fibers, they have some demerits, as well, for example, poor compatibility with different matrices and high moisture absorption and swelling property that lead to formation of cracks in brittle matrices [9].

Various chemical and physical surface modification methods have already been developed to overcome these problems. Some researchers have investigated the 
Table 1: The compositions of DPF [6].

\begin{tabular}{lrrrrr}
\hline Component & Cellulose & Lignin & Hemicellulose & $\begin{array}{c}\text { Moisture } \\
\text { content }\end{array}$ & \\
\hline Weight percent & 46 & 20 & 18 & 5 & 11 \\
\hline
\end{tabular}

Table 2: Mechanical properties of DPF $[2,5,7,8]$.

\begin{tabular}{lrrrr}
\hline $\begin{array}{l}\text { Diameter } \\
(\mu \mathrm{m})\end{array}$ & $\begin{array}{r}\text { Density } \\
\left(\mathrm{g} / \mathbf{c m}^{3}\right)\end{array}$ & $\begin{array}{r}\text { Tensile } \\
\text { strength }(\mathrm{MPa})\end{array}$ & $\begin{array}{r}\text { Young's } \\
\text { modulus }(\mathrm{GPa})\end{array}$ & $\begin{array}{r}\text { Breaking } \\
\text { strain }(\%)\end{array}$ \\
\hline $100-1000$ & $0.9-1.2$ & $58-275$ & $2-12$ & $5-19$ \\
\hline
\end{tabular}

effect of chemical treatments such as alkali treatment on interfacial adhesion between DPF and polymeric matrices and mechanical properties of their composites [3, 10-13].

Physical treatments alter the structural and surface properties of the fibers without the use of chemical agents. Among the physical methods, plasma treatment is an effective and environmentally friendly method for surface modification of natural fibers. Moreover, it is a dry method which needs no water and produces less amounts of land pollution compared with conventional methods of wet chemistry $[14,15]$. By plasma modification a rough surface can be obtained due to cleaning, ablation, or etching effect of plasma on the surface. By controlling plasma variables, such as the nature of gas, discharge power and exposure time, a great variety of surface properties can be improved, mainly wettability, roughness, and adhesion [15]. Plasma contains a mixture of reactive species like free radicals, electrons, and heavy particles with an overall zero charge density. It can bring out two types of interactions with the surface: (1) chain scission on the surface which results in surface etching, cleaning or activation that is obtained by using nonpolymerizing gases like helium, oxygen, air and nitrogen; and (2) plasma-induced polymerization or grafting, which is carried out by using various polymerizing gases and precursors like fluorocarbons, hydrocarbons and silicon-containing monomers [16].

Sinha and Panigrahi [17] showed that plasma treatment brings about hydrophobicity at jute fiber surfaces and increases the fiber surface roughness thereby increasing the interfacial adhesion with the PLA matrix. Seki et al. [18] showed that by plasma treatment, interlaminar shear strength and flexural strength in jute fiber reinforced thermoplastic composites are increased up to $35 \%$ and $30 \%$, respectively. Mechanical properties of natural fibers have been found to improve significantly after plasma treatment [19]. It is reported that fiber/ matrix adhesion after plasma treatment is improved for Arundo donax L. leaf fibers with its bio-based epoxy [20]. Sarikanat et al. [21] showed that argon and air atmospheric pressure plasma treatments improved the tensile strength, tensile modulus, flexural strength, flexural modulus, interlaminar shear strength, Mode I interlaminar fracture toughness, and Mode II interlaminar fracture toughness of flax fiber-reinforced unsaturated polyester composites. Praveen et al. [22] investigated plasma-induced effects on the surface properties of lignocellulosic natural coir fibers. The scanning electron microscopy (SEM) analysis confirmed the surface changes after plasma treatment. Etching of fiber wall was observed which led to higher water absorption. Surface lignin removal on coir fibers by plasma treatment was reported to significantly improve the adhesion in thermoplastic starch composites. Tensile strength of the composites of plasma-treated short coir fibers and thermoplastic starch increased by up to $300 \%$ and elastic modulus improved by a factor of nearly 20 times, which was associated with enhanced fiber-matrix adhesion after plasma treatment with oxygen for $7.2 \mathrm{~min}$ at $80 \mathrm{~W}$ power [23]. Enciso et al. [24] also reported a considerable improvement in tensile strength and Young's modulus of flax fiber/low-density polyethylene matrix composites after low-pressure plasma treatment on fibers.

In spite of extensive research conducted by the authors, no published studies were observed on surface modification of DPFs by plasma treatment. Therefore, the goal of this research is to investigate the effect of oxygen plasma treatment on the mechanical properties of DPFs and their interfacial adhesion to epoxy matrices. Enhancement of surface roughness of DPF is expected from plasma treatment in this work.

\section{Materials and methods}

\subsection{Preparation of materials}

The raw date palm meshes surrounding the stems of date palm trees were collected from a farm in Boushehr, Iran. The epoxy resin E-8128 and the curing agent H-3895 were both supplied by A.C.R. Tech Co., Taiwan. The fibers were washed with tap water several times to remove dirt and sand. In order to facilitate the extraction of fibers, they were retted in warm water at $50^{\circ} \mathrm{C}$ for $1 \mathrm{~h}$. After separation of fiber bundles into individual fibers, they were dried at room temperature for $24 \mathrm{~h}$ and kept in polyethylene bags until they were used. The diameter of the fibers was in 


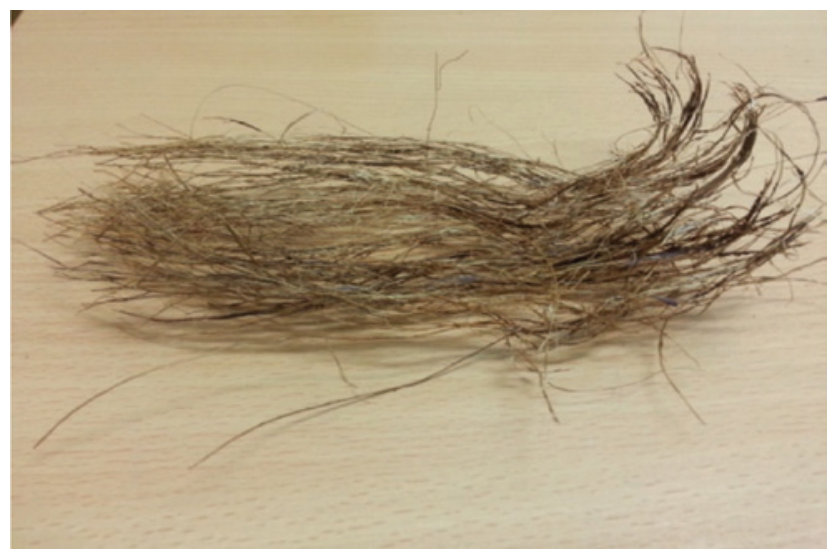

Figure 1: Extracted date palm fibers after cleaning.

the range of $310-800 \mu \mathrm{m}$ (with the average diameter of $510 \mu \mathrm{m}$ and coefficient of variation of 19.61\%). Figure 1 shows DPFs after cleaning and extraction.

\subsection{Oxygen plasma treatment}

In this work, the DPFs were treated by oxygen plasma with two discharge powers (100 and $200 \mathrm{~W}$ ) and in three different exposure times (3, 5 and $8 \mathrm{~min})$. Plasma treatment was carried out at $13.56 \mathrm{MHz}$ using the low-pressure plasma equipment, Junior plasma, from Europlasma Co., Belgium. The sample chamber was evacuated to 100 mTorr and maintained at this pressure during process. Then, oxygen was introduced with a flow rate of $100 \mathrm{sccm}$ (standard cubic $\mathrm{cm}$ per minute). Seven samples were prepared by changing the fiber treatment conditions as listed in Table 3. Sample code " $R$ " represents untreated fibers.

\subsection{Characterization techniques}

\subsubsection{Surface morphology}

The surface morphologies of untreated and treated fibers were examined using a VEGA3 SEM from TESCAN Co., Brno-Czech Republic. The surface of all the samples was coated with gold.

Table 3: Codes and characteristics of the samples.

\begin{tabular}{lrrrrrrr}
\hline Sample code & R & A3 & A5 & A8 & B3 & B5 & B8 \\
\hline Plasma power (W) & - & 100 & 100 & 100 & 200 & 200 & 200 \\
Exposure time (min) & - & 3 & 5 & 8 & 3 & 5 & 8 \\
\hline
\end{tabular}

\subsubsection{Single fiber tensile test}

Tensile properties (tensile strength, Young's modulus, and elongation to break) of treated and untreated DPFs were determined according to the instructions given in ASTM D3822 using a tensile testing machine EMT-3050, Elima Co. The gage length of $5 \mathrm{~cm}$ and crosshead speed of $1 \mathrm{~cm} / \mathrm{min}$ were employed. Twenty specimens from each treated and untreated samples were tested and the average values were reported.

\subsubsection{Weibull statistical analysis of fiber strength}

In order to obtain the measure of the variability in fiber strength, Weibull statistics were used to rank the relative fiber strength versus probability of failure of the fibers. According to the Weibull analysis, the survival probability, $P(\sigma)$, (i.e. the probability that a fiber will not break under the applied stress $\sigma$ ) is given by the Equation (1) [12]:

$$
P(\sigma)=\exp \left[-\left(\sigma / \sigma_{0}\right)^{m}\right]
$$

where $\sigma$ is the applied stress, $\sigma_{0}$ is the characteristic strength, and $m$ is the Weibull modulus. The higher the value of Weibull modulus, the less the scatter of results [15]. $(\sigma)_{i}$, the probability of survival corresponding to the $i$ th strength value is given by Equation (2) [12]:

$$
P(\sigma)_{i}=1-(i / N+1)
$$

where $N$ is the total number of fibers tested. The values of $m$ and $\sigma_{0}$ can be obtained from the slope and intercept of $\ln (\ln [(N+1) /(N+1-i)])$ versus $\ln \sigma$ according to Equation (3) [12]:

$$
\ln [\ln (N+1 / N+1-i)]=m \ln \sigma-m \ln \sigma_{0}
$$

\subsubsection{Microbond test}

The microbond test was carried out as per the procedure reported by Miller et al. [25]. The treated and untreated DPFs were mounted across a cardboard window with paper tabs as shown in Figure 2. The epoxy resin was mixed with hardener in a ratio of 2:1 as recommended by the manufacturer. Microdroplets of liquid epoxy resin were delivered to each fiber using a needle and left to be cured at room temperature for $24 \mathrm{~h}$. Then, the diameter of each fiber and the embedded length were measured using a Projectina microscope to compute the embedded 


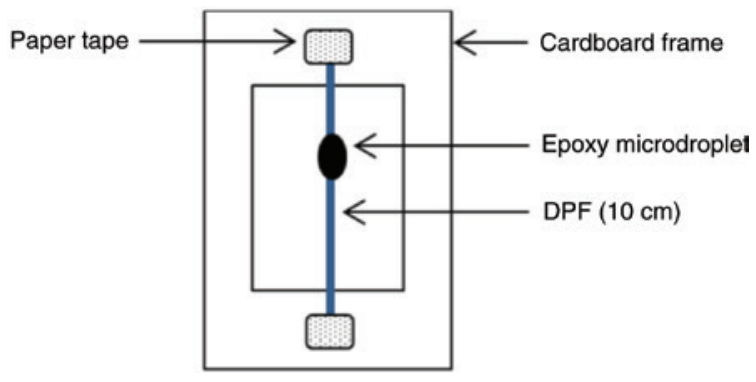

Figure 2: Schematic representation of template used in the preparation of samples for microbond test.

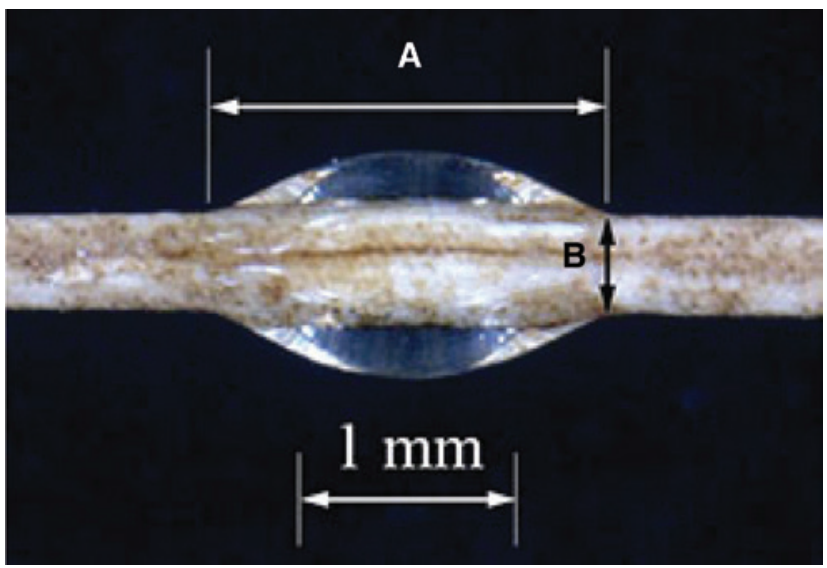

Figure 3: Enlarged image of epoxy microdroplet on DPF surface; (A) embedded length and (B) fiber diameter.

area, which is the surface area of the fiber in contact with the resin. Figure 3 shows an enlarged image of an epoxy droplet on a date palm fiber. The microbond test was performed using the tensile testing machine EMT3050. A pair of blades was designed to grip the droplet (Figure 4). The small gap between the blades was controlled so that only the main body of the fiber can pass through it. As illustrated in Figure 4, the blades were mounted on the lower jaws of the tester. The fiber was moved by the upper jaws between the blades at a rate of $1 \mathrm{~mm} / \mathrm{min}$ until complete debonding of the droplet from the fiber occurs. Thirty specimens from each sample were tested. The average peak load was then determined and used to calculate the interfacial shear stress using Equation (4) [25]:

$$
\tau=F / d_{\mathrm{f}} \pi l_{\mathrm{e}}
$$

where $F$ is the peak load recorded during the experiment, $l_{\mathrm{e}}$ is the embedded length, and $d_{\mathrm{f}}$ is the diameter of the fiber.

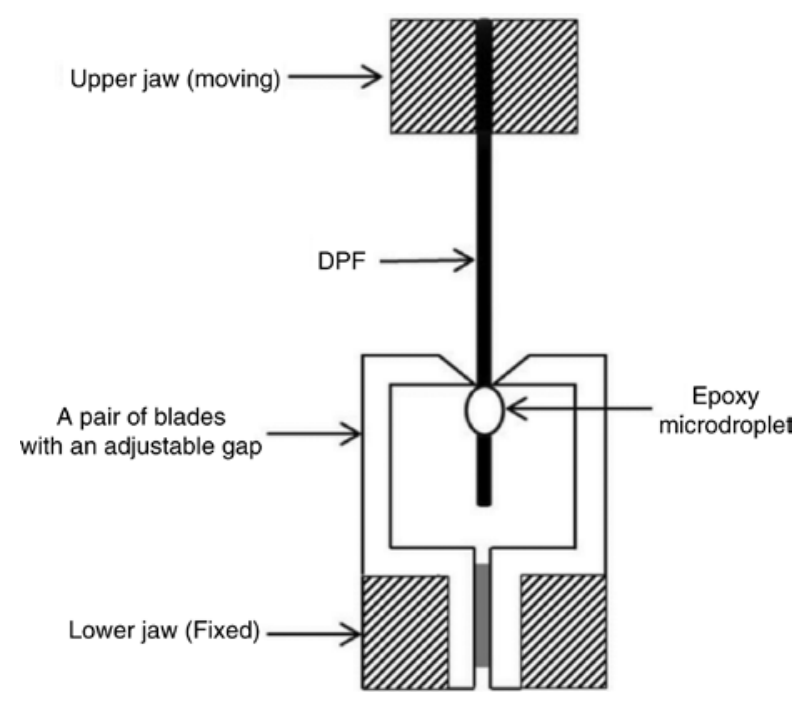

Figure 4: Schematic diagram of the microbond test.

\subsubsection{Statistical analysis}

In order to analyze the peak load values, one-way analysis of variance (ANOVA), was performed using the SPSS Statistical Software. All multiple-comparisons were performed by the Tukey's method.

\subsubsection{Attenuated total reflectance-Fourier transform infrared spectroscopy (ATR-FTIR)}

The effect of oxygen plasma treatment on the functional groups of fibers was investigated by attenuated total reflectance-Fourier transform infrared spectroscopy (ATRFTIR) analysis. Infrared spectra were obtained using a Bomem MB100 (Hartman and Braun, Canada) infrared spectrophotometer with a resolution of $4 \mathrm{~cm}^{-1}$. An average of 40 scans was recorded. The spectrometer was used in the reflection mode in the range of $4000-400 \mathrm{~cm}^{-1}$.

\section{Results and discussion}

\subsection{Effect of plasma treatment on the surface characteristics of the fibers}

The micrographs of the fibers before and after oxygen plasma treatment can be seen in Figures 5 and 6, respectively. The raw DPF is cylindrical in shape and there are some impurities as shown in Figure 5. Moreover, a waxy layer can be observed on the surface of the fiber. This layer 


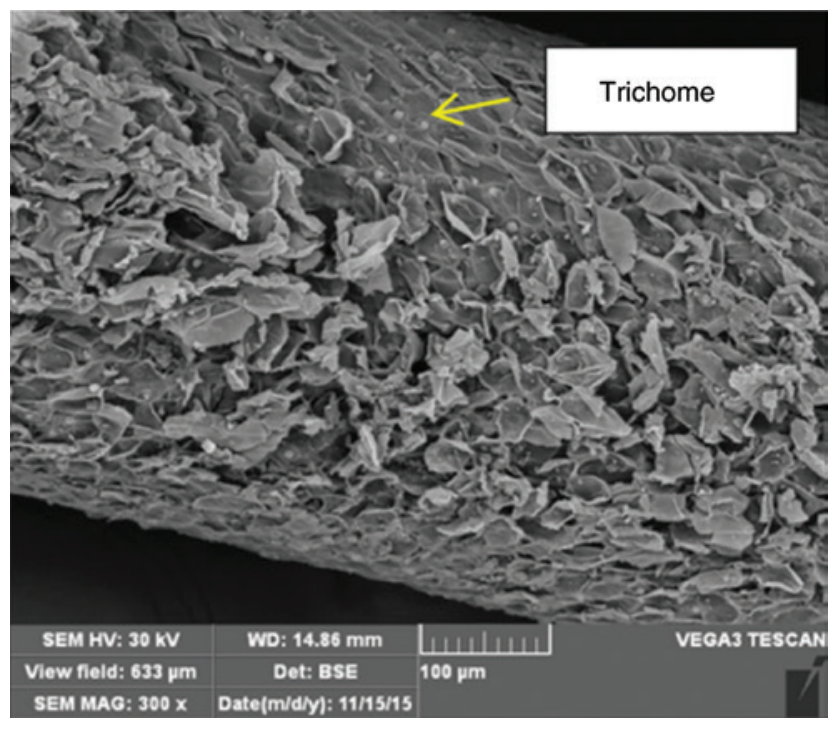

Figure 5: Micrographs of untreated DPFs.

has covered the trichomes in some regions. As can be seen in Figure 6, plasma treatment removes the waxy layer and thus improves the surface wettability of the fiber. It is seen that by removing the waxy layer, the trichomes appear in more regions. Furthermore, by increasing the exposure time to $8 \mathrm{~min}$, the trichomes are destroyed and the grooves underneath them appear in some regions. In some studies on the effect of alkaline concentration on the DPF, similar observations have been reported $[2,10]$. As can be seen in Figure 6C,D, increasing the plasma power to $200 \mathrm{~W}$, leads to higher surface roughness on the fibers. This is attributed to the etching effect caused by the bombardment of the oxygen plasma species on the fiber surface $[15,26]$.

\subsection{Attenuated total reflectance-Fourier transform infrared spectroscopy analysis}

The ATR-FTIR spectra of raw and plasma-treated DPFs are shown in Figure 7. In these spectra very strong and broad bands in the range of $3000-3600 \mathrm{~cm}^{-1}$ are due to stretching vibrations of $\mathrm{O}-\mathrm{H}$ groups. The bands in the range of $2800-3000 \mathrm{~cm}^{-1}$ are related to stretching vibrations of $\mathrm{C}-\mathrm{H}$ in saturated hydrocarbons. The peak at around $1726 \mathrm{~cm}^{-1}$ is due to carbonyl $(\mathrm{C}=0)$ stretching of acetyl groups of
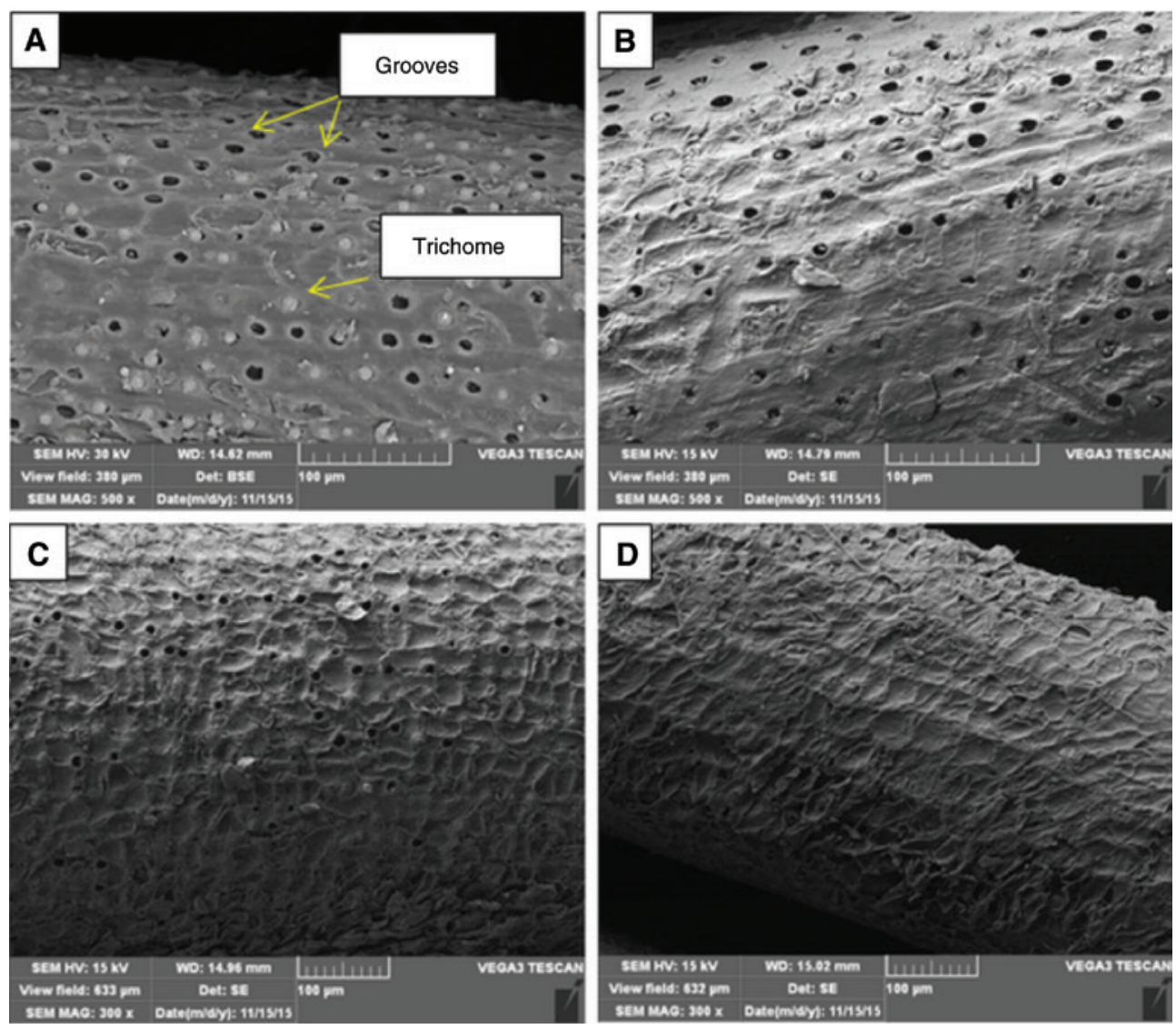

Figure 6: Micrographs of plasma-treated DPFs under different conditions: (A) A3, (B) A8, (C) B3, and (D) B8. 


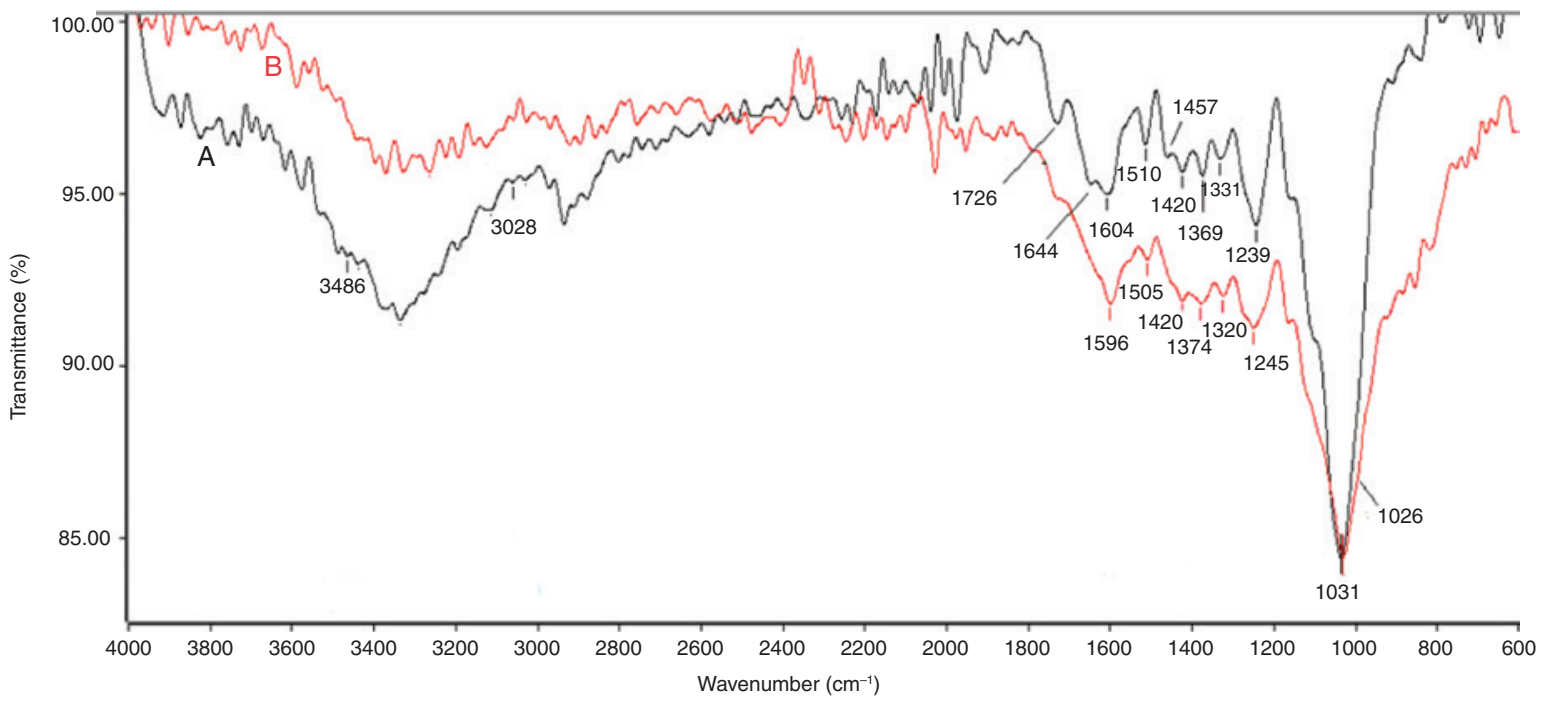

Figure 7: FTIR spectra of (A) raw and treated DPF with discharge power of $100 \mathrm{~W}$ and (B) exposure time of $5 \mathrm{~min}$.

hemicellulose or ester linkages of carboxyl groups of lignin and hemicellulose $[13,15,27]$. After plasma treatment, decreasing intensity of this peak in the spectra may be due to the decrease in hemicellulose content. The bands at 1510 and $1604 \mathrm{~cm}^{-1}$ are attributed to aromatic skeleton vibrations assigned to lignin [13, 28-30]. In the spectra of the treated fiber, these bands shifted towards 1505 and $1596 \mathrm{~cm}^{-1}$, respectively. This is possibly due to the decrease in lignin components. After plasma treatment, intensity of the band at $1420 \mathrm{~cm}^{-1}$ has decreased. In general, the bands in the range $1400-1430 \mathrm{~cm}^{-1}$ are related to the $\mathrm{C}-\mathrm{H}$ deformation for methoxy group in the structure of lignin [30]. The band near $1369 \mathrm{~cm}^{-1}$ is possibly due to a $\mathrm{CH}_{3}$ bending that in the treated fiber spectra is shifted towards $1374 \mathrm{~cm}^{-1}[2,31]$. The peak at $1239 \mathrm{~cm}^{-1}$ may be attributed to $\mathrm{C}-\mathrm{O}-\mathrm{C}$ stretching vibration and $\mathrm{O}-\mathrm{CH}$ deformation from phenolic group [28, 30]. After plasma treatment, this band was observed at $1245 \mathrm{~cm}^{-1}$. The strong band about $1031 \mathrm{~cm}^{-1}$ is ascribed to the $\mathrm{C}-\mathrm{O}$ and $\mathrm{C}-\mathrm{OH}$ stretching vibration which belongs to cellulose [26]. In the treated fiber spectra, this peak is near $1026 \mathrm{~cm}^{-1}$.

\subsection{Single fiber tensile properties}

Average tensile strength and modulus values of untreated (raw) and treated single fibers are compared in Figure 8. It is seen that plasma treatment improves both tensile strength and Young's modulus. According to Morent et al. [32] changing the physical properties of yarns and fabrics, and more in particular their increase in tensile strength, bursting strength and wear resistance are some positive effects caused by plasma treatment on textile structures. The significant increase in tensile strength and Young's modulus of banana fibers after plasma treatment is also reported by Oliveira et al. [19]. However, it should be noted that in some previous works the decrease in mechanical properties of natural fibers after plasma treatment was reported. It was attributed to the heat generated during the plasma treatment which causes dehydration of the fibres, the etching effect of plasma which degrades their macrofibril structure and generation of micropits and voids on the surface of fibers [33,34].

The maximum tensile strength and Young's modulus values are obtained for A8 and B3 samples, respectively. The values of tensile strength of the treated fibers at $200 \mathrm{~W}$ power are slightly lower than samples at $100 \mathrm{~W}$ power. Similar observations are seen in Young's modulus values for 5 and 8 min treatment time. It may be due to producing more cracks and damages on the surface of the fiber with increasing intensity of plasma, as shown in Figure 6D. One-way ANOVA analysis showed significant differences between untreated and treated samples. However, the effects of plasma power and exposure time on tensile properties of DPF are not found significant.

\subsection{Weibull distribution of the tensile strength of DPF}

Figure 9 shows the Weibull distribution of the tensile strength of raw and treated DPF. The Weibull modulus values for natural date palm fiber are much lower compared to that of synthetic fibers such as glass fiber [12]. 
A

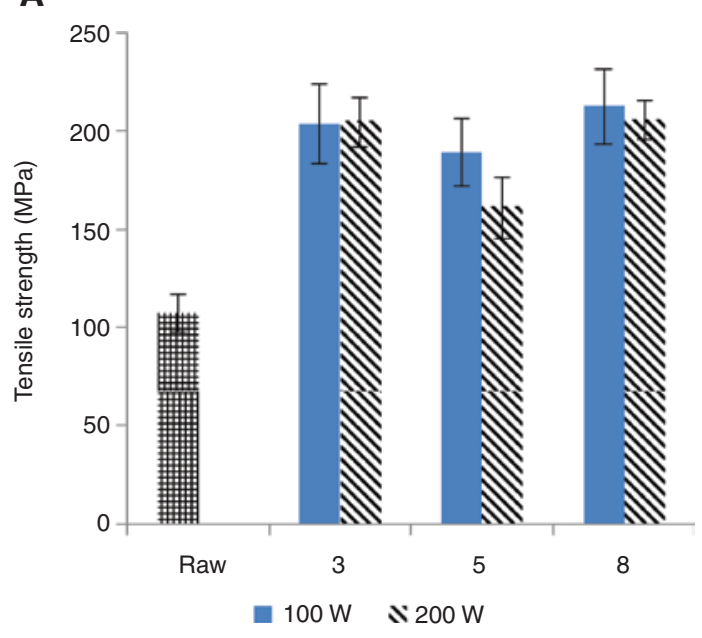

B

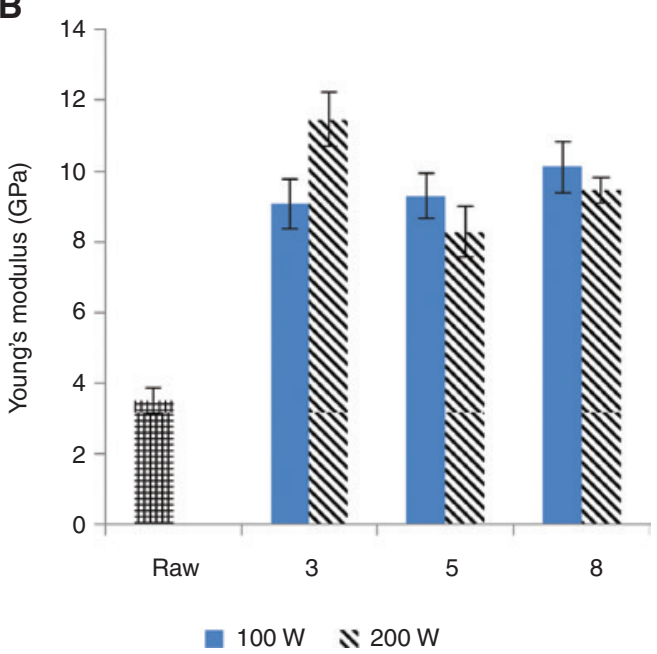

Figure 8: Treatment conditions: two discharge powers (100 W and $200 \mathrm{~W}$ ) and three exposure times (3,5 and $8 \mathrm{~min})$. (A) Tensile strength and (B) Young's modulus of treated and untreated DPFs.

A

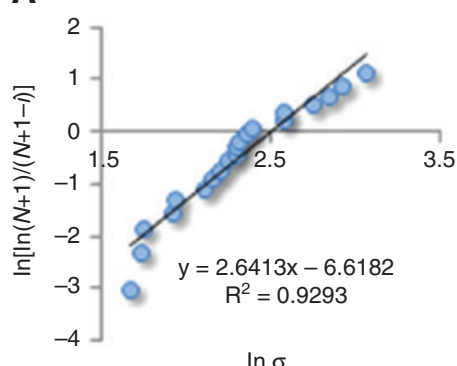

D

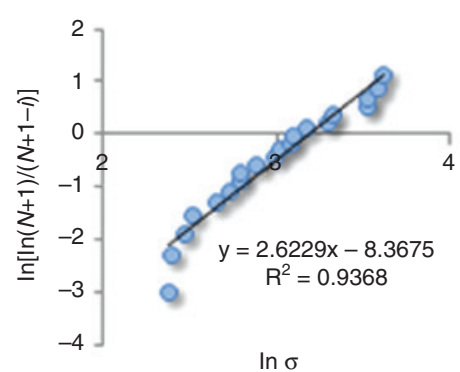

B

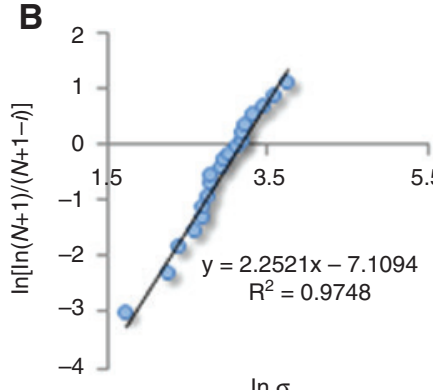

E

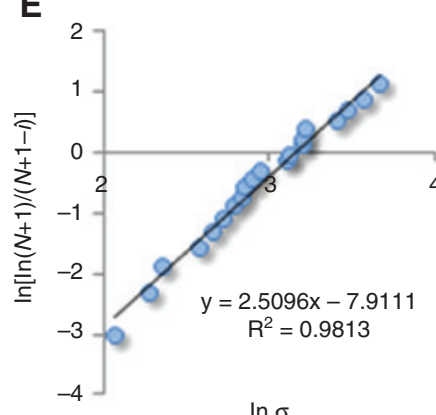

$\ln \sigma$

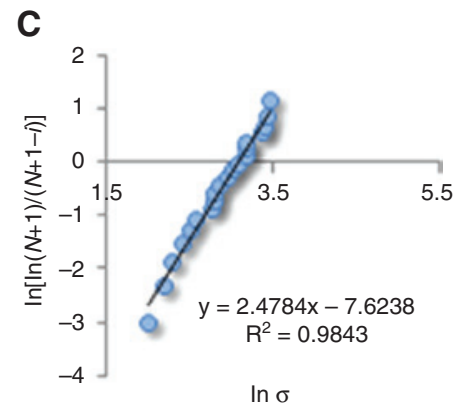

F

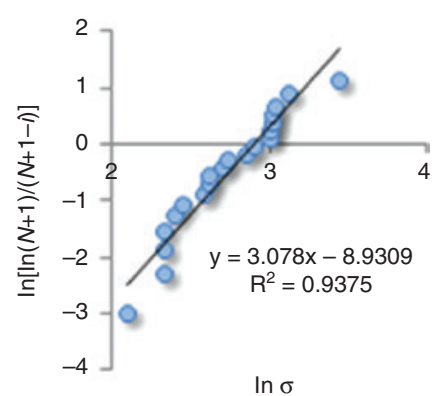

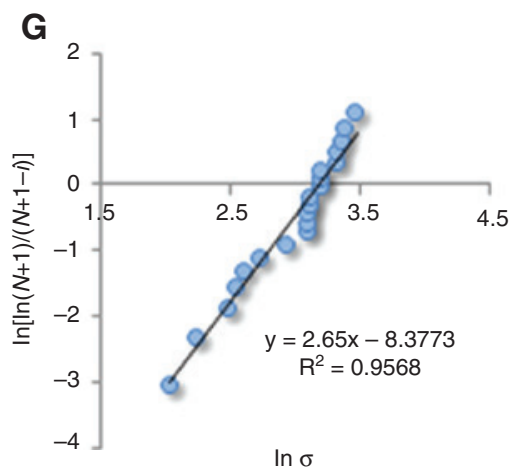

Figure 9: Weibull distribution of the tensile strength of DPFs: (A) R, (B) A1, (C) A2, (D) A3, (E) B1, (F) B2, and (G) B3. 
This could be due to the nonhomogeneous nature of natural fibers and irregular fiber diameter. On the other hand, the Weibull modulus of DPFs after plasma treatment has not increased significantly. This indicates that plasma treatment could not decrease the variability in fiber strength due to the nature of fibers.

\subsection{Microbond test analysis}

It is well known that mechanical properties of composites are largely controlled by the interface, which is usually required to be strong in polymer matrix composites, thus transferring load from the matrix to the fibers efficiently [14]. The IFSS values which were calculated using Equation (1) are shown in Figure 10. It can be seen that plasma treatment has increased the IFSS values of DPFs. The maximum IFSS value is obtained at $100 \mathrm{~W}$ and $5 \mathrm{~min}$. This is attributed to the cleaning process and etching effect of plasma species that result in fiber-matrix adhesion improvement. The surface of the fiber has roughened and the waxy layer and impurities have been removed. Plasma treatment improves the fiber-matrix adhesion largely by increasing friction and mechanical interlocking between the fiber and the matrix [15]. According to the ANOVA analysis, there is a significant difference between the IFSS values of treated and untreated samples. However, the effects of plasma power and exposure time on IFSS values of DPF are not found significant. Figure 11 shows a treated specimen after microbond test.

Plasma treatment positively affects the strength of DPF and its interfacial adhesion with the matrix.

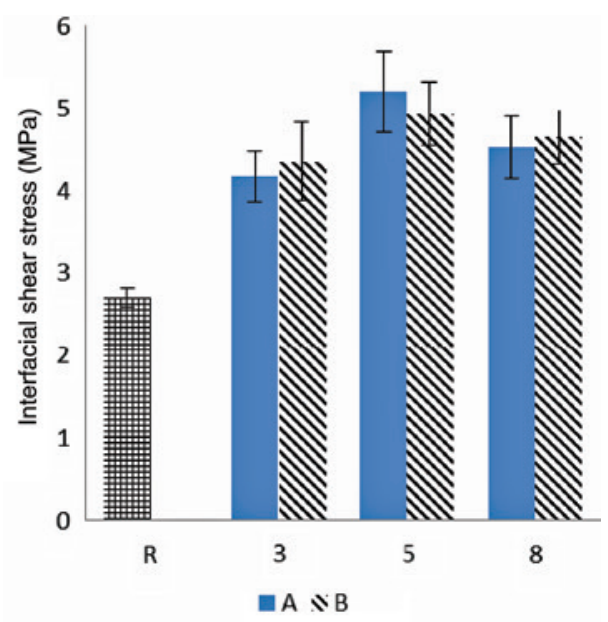

Figure 10: IFSS values of the samples.

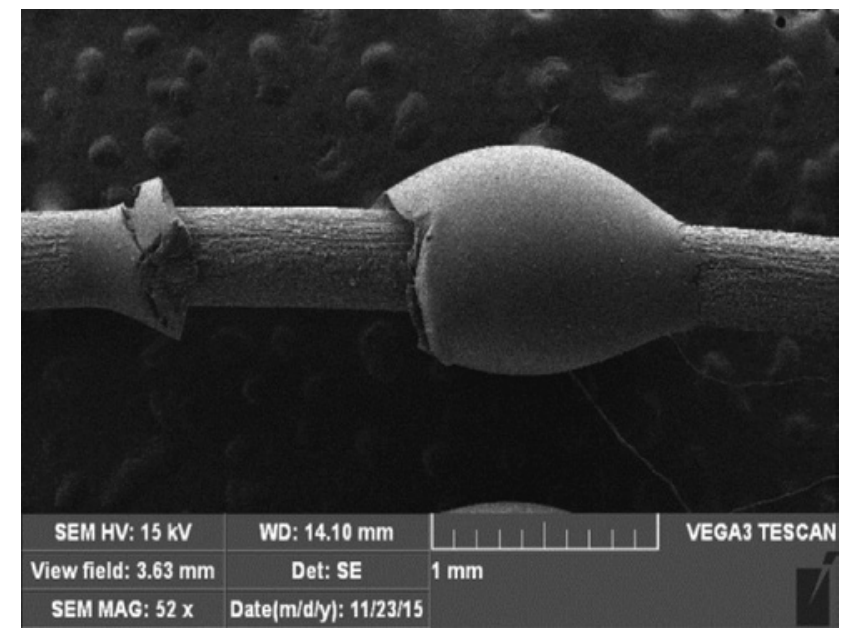

Figure 11: Micrograph of debonded epoxy microdroplet on a treated fiber surface.

Reducing lignin and hemicellulose content, etching and cleaning surface, and increasing mechanical interlocking between fibers and matrix can improve fiber-matrix adhesion.

\section{Conclusions}

In this work, the influence of oxygen plasma treatment on tensile strength of DPF and the interfacial adhesion between DPF and epoxy was studied. According to the results of single fiber tensile strength test, there is a significant improvement in tensile strength and Young's modulus values of DPFs after plasma treatment. It was observed that plasma treatment cleans the surface of DPF by removing waxy layer and impurities and increases surface roughness which results in enhancing friction and mechanical interlocking between fiber and epoxy resin. Based on the results of microbond test, surface modification of fibers by plasma could improve interfacial adhesion between DPF and epoxy matrix. However, the effects of plasma power and exposure time on tensile properties and IFSS values were not found significant; however, the maximum IFSS value was obtained at $100 \mathrm{~W}$ and $5 \mathrm{~min}$. The Weibull modulus of DPFs after plasma treatment did not increase significantly. This may be due to that plasma treatment could not decrease the variability in fiber strength caused by nature of fiber. The ATR-FTIR analysis showed alterations in stretching vibrations of $\mathrm{C}=\mathrm{O}, \mathrm{C}-\mathrm{O}-\mathrm{C}, \mathrm{C}-\mathrm{O}$, $\mathrm{C}-\mathrm{OH}$ groups and aromatic skeleton vibrations after 
plasma treatment. This may be due to decrease of lignin and hemicellulose components.

\section{References}

[1] Sreekumar AP, Thomas S. In Properties and Performance of Natural-Fibre Composites, 1st ed., Pickering, KL, Ed., Woodhead Publishing Limited: Cambridge, England, 2008, pp 67-71.

[2] Alawar A, Hamed AM, Al-Kaabi KH. Compos. Part B Eng. 2009, 40, 601-606.

[3] Alsaeed T, Yousif BF, Ku H. Mater. Design 2013, 43, 177-184.

[4] Thakur VK, Thakur MK, Gupta RK. Int. J. Polym. Anal. Charact. 2014, 19, 256-271.

[5] Al-Oqla FM, Alothman OY, Jawaid M, Sapuan SM, Es-Saheb MH. In Biomass and Bioenergy, 1st ed., Hakeem, KHR, Jawaid, M, Rashid, U, Eds., Springer International Publishing: Switzerland, 2014, pp 1-25.

[6] Al-Oqla FM, Sapuan SM. J. Clean Prod. 2014, 66, 347-354.

[7] Al-Oqla FM, Salit MS, Ishak MR, Aziz NA. Bioresour. Technol. 2014, 9, 4608-4621.

[8] Al-Khanbashi A, Al-Kaabi KH, Hammami A. Polym. Compos. 2005, 26, 486-497.

[9] Cruz J, Fangueiro R. Proc. Eng. 2016, 8, 155-285.

[10] Shalwan A, Yousif BF. Mater. Design 2014, 53, 928-937.

[11] Wazzan AA. Int. J. Polym. Mater. 2006, 55, 485-499.

[12] Elbadry EA. J. Compos. 2014, 2014, 1-8.

[13] Taha I, Steuernagel L, Ziegmann G. Compos. Interface 2007, 14, 669-684.

[14] Gibeop N, Lee DW, Prasad CV, Toru F, Kim BS, Song JI. Adv. Compos. Mater. 2013, 22, 389-399.

[15] Bozaci E, Sever K, Sarikanat M, Seki Y, Demir A, Ozdogan E, Tavman I. Compos. Part B Eng. 2013, 45, 565-572.

[16] Kalia S, Thakur K, Celli A, Kiechel MA, Schauer CL. Environ. Chem. Eng. 2013, 1, 97-112.
[17] Sinha E, Panigrahi S. J. Compos. Mater. 2009, 43, 1791-1802.

[18] Seki Y, Sever K, Sarikanat M, Güleç HA, Tavman IH. In 5th International Advanced Technologies Symposium (IATS'09), May 13-15, Karabük, Turkey, 2009, 1007-1010.

[19] Oliveira F, Erkens L, Fangueiro R, Souto A. Plasma Chem. Plasma P. 2012, 32, 259-273.

[20] Scalici T, Fiore V, Valenza A. Compos. Part B Eng. 2016, 94, 167-175.

[21] Sarikanat M, Seki Y, Sever K, Bozaci E, Demir A, Ozdogan E. J. Ind. Text. 2016, 45, 1252-1267.

[22] Praveen KM, Thomas S, Grohens Y, Mozetič M, Junkar I, Primc G, Gorjanc M. Appl. Surf. Sci. 2016, 368, 146-156.

[23] de Farias JG, Cavalcante RC, Canabarro BR, Viana HM, Scholz S, Simão RA. Carbohyd. Polym. 2017, 165, 429-436.

[24] Enciso B, Abenojar J, Martínez MA. Cellulose 2017, 24, 1791-1801.

[25] Miller B, Muri P, Rebenfeld L. Compos. Sci. Technol. 1987, 28, 17-32.

[26] Amirou S, Zerizer A, Haddadou I. Sci. Res. Essays 2013, 8, 946-952.

[27] Rayung M, Ibrahim NA, Zainuddin N, Saad WZ, Razak NI, Chieng BW. Int. J. Mol. Sci. 2014, 15, 14728-14742.

[28] Sinha E. Compos. Mater. 2009, 43, 1791-1802.

[29] Shafiei M, Karimi K, Taherzadeh MJ. Int. J. Mol. Sci. 2010, 11, 4285-4296.

[30] Mosiewicki MA, Marcovich NE, Aranguren MI. In Interface engineering of natural fibre composites for maximum performance, 1st ed., Zafeiropoulos, NE, Ed., Woodhead Publishing: Cambridge, 2011, p 122.

[31] Abdal-Hay A, Suardana NP, Jung DY, Choi KS, Lim JK. Int. J. Precis. Eng. Manuf. 2012, 13, 1199-1206.

[32] Morent R, Geyter N, Verschuren J, Clerck K, Kiekens P, Leys C. Surf. Coat. Technol. 2008, 202, 3427-3449.

[33] Baltazar-y-Jimenez A, Bistritz M, Schulz E, Bismarck A. Compos. Sci. Technol. 2008, 68, 215-227.

[34] Bozaci E, Sever K, Demir A, Seki Y, Sarikanat M, Ozdogan E. Fiber Polym. 2009, 10, 781-786. 